\title{
A survey of the use of the electrocardiogram in psychiatry
}

\author{
Tom Henderson, Dominic Gallagher and Cameron Stark
}

\begin{abstract}
A survey was undertaken to ascertain if doctors working in poychiatry knew when to pertorm electrocardograms (ECGs) prior to and during psychlatic treatments where indicated, and to investigate the training, confidence and ablitty of doctors in ECG interpretation. Half had recelved no training in the indications for pertorming on ECG. Opinion aiflered widely as to when to pertorm an ECG. with 54\% stating an ECG was required before treatment with pimozdde and only $19 \%$ and $11 \%$ stating ECEs were required during the course of treatment with pimozide and high dose entipsycholic medication respectively.

Ability in ECG interpretation correlated negatively with time spent in peychiatry but no correlation existed between grade and ablity to identily an ECG as normal or abnormal.
\end{abstract}

Many psychotropic medications are associated with cardiovascular side-effects. The Royal College of Psychiatrists' Consensus Statement on the use of High Dose Antipsychotic Medication (1993) recommends performing an electrocardiogram (ECG) prior to commencing patients on high dose antipsychotic medication, as well as performing regular ECGs while such treatments continue.

The data sheets for some psychotropic medications contain guidance as to when an ECG should be performed prior to and during the course of treatment with, for example, pimozide (Association of British Pharmaceutical Industries, 1996). However, such clear guidance is unavailable for the majority of psychotropic medications, some of which have known cardiovascular side-effects, for example lithium preparations.

This study was undertaken to ascertain if doctors working in psychiatry were adhering to the College Consensus Statement and knew when to perform ECGs prior to and during treatment. In addition, the survey investigated the training, confidence and ability of doctors in ECG interpretation.

\section{The study}

A self-completion questionnaire was distributed to 70 doctors of varying grades in a number of Glasgow hospitals during the course of academic activities, such as case conferences and journal clubs. Doctors were asked to complete the questionnaires, without consulting colleagues or textbooks, and return them at the end of the session. The questionnaire enquired about doctors' training and confidence in the use of and interpretation of ECGs as well as their routine use of ECGs in clinical practice. Doctors were also asked to comment on whether a range of 10 ECGs were normal or not, and to comment on the nature of any abnormality identified. A general physician had selected a range of normal and abnormal ECGs which he felt a junior house officer should be able to interpret. Responses were collated and analysed using Epi Info 5, a computer software program.

\section{Findings}

Sixty-three of the 70 questionnaires were returned. Respondents included 13 general practice vocational trainees, 17 psychiatric senior house officers (SHOs), 11 registrars, 10 senior registrars, 11 consultants and one associate specialist. Respondents had spent a median of 36 months in psychiatry (range 1-276 months). Of the $\mathbf{5 0}$ career psychiatrists, 30 had spent a median of 18 months in other specialities (range 6-120). Nine of the respondents had passed Part 1 and 23 Part 2 of the MRCPsych examination. Nine respondents (all career psychiatrists) had passed the MRCGP examination and one (also a psychiatrist) held the MRCP. Other postgraduate qualifications, such as the DRCOG and the $\mathrm{DCH}$, were held by 12 respondents.

\section{Training}

Doctors were asked what training they had received in ECG interpretation during their careers. Fifty-four $(85.7 \%)$ had received such training as medical students, $44(69.8 \%)$ as preregistration house officers and $18(28.6 \%)$ while working in non-psychiatric post-registration specialities. Only one had received any training while working in psychiatry. Twenty-nine (46\%) had taken steps to improve their knowledge in ECG interpretation, with 25 of them consulting an appropriate textbook. 
Doctors were also asked if they had received any training, while working in psychiatry, as to when an ECG is indicated for patients receiving certain psychiatric treatments. Thirty-two (50.8\%) stated they had received no teaching, $18(28.6 \%)$ recalled informal teaching and 18 (28.6\%) reported self-instruction by consulting textbooks. Only $8(12.7 \%)$ and $5(7.9 \%)$ recalled such teaching at a postgraduate lecture or seminar respectively.

\section{Confidence}

Respondents were asked to rate how confident they felt when interpreting ECGs by means of a 5 point Likert scale ranging from not at all confident' to 'very confident'. Thirty-seven $(58.7 \%)$ rated less than 3 . Twenty-six $(41.7 \%)$ rated 3 or 4 , but none 5 . Nineteen of the 26 scoring 3 or over were SHOs $\left(\chi^{2}: P<0.001\right)$. A higher proportion of GP trainees scored 3 or over $(P<0.05)$.

\section{Indications for performing an ECG pre-treat- ment}

Respondents were asked if they would perform an ECG prior to commencing a healthy 30-yearold on a variety of psychotropic medications or a course of electroconvulsive therapy (ECT). For the following treatments, the percentages answering yes were as follows: ECT, 61.9\%; pimozide, 54\%, lithium, 50.8\%; disulfiram, 28.6\%; clozapine, 25.4\%; amitriptyline, $14.3 \%$; phenelzine, $9.5 \%$; mianserin, $9.5 \%$; flupenthixol, $3.2 \%$; haloperidol, 1.6\%; paroxetine, and chlordiazepoxide, $0 \%$.

Responses were analysed for the four treatments most commonly reported as being an indication for a pre-treatment ECG by dividing respondents into those without any psychiatric qualifications and those with Part 1 or 2 of the MRCPsych. There was no difference between the two groups with regard to performing an ECG prior to treatment with ECT or lithium. Those in the latter group, however, were significantly more likely to perform an ECG before commencing treatment with pimozide $\left(\chi^{2}\right.$ with Yates correction: $P<0.001$ ) or disulfiram ( $\chi^{2}$ with Yates correction: $P<0.05)$.

\section{Indications for performing an ECG during treatment}

Respondents were asked if there were any situations when someone was already receiving any of the above treatments, in which they would wish to perform an ECG. The answers given were: cardiac abnormality, $77.8 \%$; overdose, $20.6 \%$; ongoing treatment with pimozide, $19 \%$; high dose antipsychotic treatment, $11.1 \%$; metabolic disorder, $11.1 \%$; phenelzine, $1.6 \%$ and various miscellaneous reasons, $19 \%$. Those with Part 1 or 2 of the MRCPsych were not more likely to perform an ECG on patients receiving high dose antipsychotic medication, but were more likely to do so for patients on pimozide $(P<0.05)$.

\section{Out-patient versus in-patient}

Twenty-three (36.5\%) respondents stated they would be less likely to perform an ECG on an outpatient, $35(55.6 \%)$ stated it would make no difference and three $(4.8 \%)$ stated they would be more likely to perform an ECG on an out-patient.

\section{Ability in ECG interpretation}

One point was given for correctly identifying an ECG as normal or abnormal and a further point given for identifying what the abnormality, if present, was. The highest score possible was 20 .

The median total score obtained was 14 (range 0-19) and the median number of correct diagnoses identified was 5 (range 0-9). There was only a slight correlation between respondents' total score and their reported confidence in ECG interpretation $\left(R^{2}=0.08,95 \% \mathrm{CI} 0.03-0.5\right)$. There was no correlation between the total number of normals/abnormals identified and reported confidence.

There was no correlation between grade and the number of normal and abnormal ECGs identified. However, there was a negative correlation between time spent in psychiatry and total score $\left(R^{2}=0.14,95 \% \mathrm{CI}-0.57--0.13\right)$.

\section{Comment}

The response rate of $90 \%$ was satisfactory. The authors do recognise that in clinical practice doctors are likely to consult other colleagues or appropriate textbooks if they are in any doubt as to when to perform or how to interpret an ECG. The results, therefore, may not fully reflect routine clinical practice.

The fact that 62 doctors had not received any training in ECG interpretation while working in psychiatry is hardly surprising. It may be of greater concern that 32 doctors $(50.8 \%)$ reported no training in deciding when ECGs are indicated in patients receiving psychiatric treatments.

The lack of uniformity in respondents' replies on indications for a pre-treatment ECG may reflect a diversity in routine psychiatric practice. It may, however, also reflect the fact that little training seems to occur in this area and that doctors replying to this question were simply unclear as to when an ECG is indicated. Doctors with Parts 1 or 2 of the MRCPsych were more likely to perform an ECG prior to treatment with pimozide, which the data sheet clearly recommends, and disulfiram, in the authors' view, 
advisable. This suggests that this knowledge seems to be acquired by some in the course of psychiatric training, but only $50.8 \%$ and $28.6 \%$ of the total sample felt that an ECG was indicated prior to commencing these respective treatments.

Few respondents indicated they would perform an ECG when a patient is already receiving treatment with either pimozide or high dose antipsychotic medication. The data sheet for pimozide states regular monitoring of cardiac function should occur when using doses exceeding $16 \mathrm{mg}$ daily and the College consensus statement on the use of high dose antipsychotic medication suggests that ECGs should be repeated every 1-3 months on patients receiving such treatment. Doctors, in our sample, were clearly not adhering to such guidance.

Over one-third of the total sample reported that they would be less likely to perform an ECG on an out-patient. There is no clinical rationale for such a decision.

Senior house officers and GP trainees felt more confident about interpreting ECGs. There was, however, only a slight correlation between confidence and total score. The total score obtained was negatively correlated with time spent in psychiatry but there was no correlation between grade and the number of normal and abnormal ECGs identified, indicating that the majority of psychiatrists are at least able to identify an ECG as being abnormal and could conceivably seek further advice if necessary.
This study confirms that doctors working in psychiatry receive little training as to when it is appropriate to perform an ECG, before and during psychiatric treatments, where an ECG may be indicated. This lack of training may explain the fact that a significant proportion of doctors do not appear to perform ECGs in situations where this is clearly indicated. There is a need for ongoing training in this area and the implementation of clearer, more comprehensive guidelines may facilitate this.

\section{References}

association of Brtish Pharmaceutical industries (1996) ABPI Data Sheet Compendium (1995-96). London: Datapharm Publications limited.

Royal College of PSYchiatrists (1993) Consensus Statement on the use of High Dose Antipsychotic Medication. Council Report, CR26. London: RCPsych.

*T. Henderson, Senior Registrar in Psychiatry, Dykebar Hospital, Grahamston Road, Paisley PA2 7DE; D. Gallagher, Career Registrar in Psychiatry. Monklands and Bellshill Hospitals, NHS Trust, Monkscourt Avenue, Airdrie ML6 OJS; C. Stark, Consultant in Public Health Medicine, Ayrshire and Arran Health Board, Seafield House, Doonfoot Road, Ayr KA7 4DW

*Correspondence 